parental anxiety might prompt differences in parent-infant interaction that in turn might be reflected in altered sleep or autonomic function. If so, this might explain many of the subtle changes in HR and breathing pattern observed in near-SIDS and siblings $(3,5,6)$.

We cannot determine from this retrospective study whether the abnormalities in heart rate and respiratory spectra identified in these infants are causally related to SIDS. Our results suggest the need for a prospective study in which similar data could be examined prior to the occurrence of symptoms.

Acknowledgments. We acknowledge the expert support of Dr. Adrian Wilson, Department of Medical Physics, Royal Haillamshire Hospital, Sheffield, England and Dr. Stephen Burns, Harvard-MIT Biomedical Engineering Center for their suggestions and implementation of electronic preprocessing methods to eliminate wow and flutter of the time base of the cassette record signals. We thank Robert Kenet for useful discussions and advice with regard to the digital processing algorithms.

\section{REFERENCES}

1. Akselrod S, Gordon D, Ubel FA, Shannon DC, Barger AC, Cohen RJ 1981 Power spectrum analysis of heart rate fluctuation: a quantitative probe of beat-to-beat cardiovascular control. Science 213:220

2. Guilleminault C, Ariagno RL, Forno LS, Nagel L, Baldwin R, Owen M 1979 Obstructive sleep apnea and near miss for SIDS. 1. Report of an infant with sudden death. Pediatrics 63:837
3. Harper RM, Leake B, Hoffman H, Walter DO, Hoppenbrouwers T, Hodgman J. Sterman MB 1981 Periodicity of sleep states is altered in infants at risk for the sudden infant death syndrome. Science 213:1030

4. Jacobs DLR 1974 Introduction to Control Theory. Clarendon Press, Oxford

5. Katona PG, Egbert JR 1978 Heart rate and respiratory rate differences between pre-term and full-term infants during quiet sleep: possible implications for sudden infant death syndrome. Pediatrics 62:1

6. Kelly DH, Shannon DC 1979 Periodic breathing in infants with near-miss sudden infant death syndrome. Pediatrics 63:355

7. Kitney RI, Rompelman O 1980 The Study of Heart Rate Variability. Clarendon Press, Oxford

8. Naeye RL 1973 Pulmonary arterial abnormalities in the sudden infant death syndrome. N Engl J Med 289:1167

9. Porges SW 1984 Perspectives in Cardiovascular Psychophysiology. Guilford Press, New York, in press

10. Salk L, Grellong BA, Deitrich J 1974 Sudden infant death. Normal cardiac habituation and poor autonomic control. N Engl J Med 291:219-222

11. Sayers B McA 1973 Analysis of heart rate variability. Ergonon 16:17

12. Schluter PS 1981 Design and evaluation of a bedside cardiac arrhythmia monitor. PhD thesis, Massachusetts Institute of Technology

13. Shannon DC, Kelly D 1977 Impaired regulation of alveolar ventilation and the sudden infant death syndrome. Science 197:367

14. Stalcup SA, Lipset JS, Legant PM, Leuenberger PJ, Mellins RB 1979 Inhibition of converting enzymes activity by acute hypoxia in dogs. J Appl Physiol 46:227

15. Stein IM, Shannon DC 1975 The pediatric pneumogram: a new method for detecting apnea in infants. Pediatrics 55:598

16. Steinschneider A: Prolonged apnea and the sudden infant death syndrome: clinical and laboratory observations. Pediatrics 50:646

17. Takashima S, Armstrong D, Becker L, Bryan AC 1978 Cerebral hypoperfusion in the sudden infant death syndrome? Brainstem gliosis and vasculature. Ann Neurol 4:257

\title{
Prenatal Thyroid Function Abnormalities in Infants with Idiopathic Respiratory Distress Syndrome
}

\author{
VAL ABBASSI, JAMES ADAMS, DANIEL DUVALL, AND ELIZABETH PHILLIPS \\ Department of Pediatrics, Georgetown University School of Medicine, Washington, D. C. 20007
}

\begin{abstract}
Summary
Thyroxine $\left(\mathrm{T}_{4}\right)$, triiodothyronine $\left(\mathrm{T}_{3}\right)$, and thyrotropin (TSH) concentrations were measured on cord sera of 21 preterm infants with idiopathic respiratory distress syndrome (IRDS) and were compared to the values obtained from 15 healthy preterm infants. When $\log T_{3}, \log T_{4}$, and $\log$ TSH were considered as the dependent variables in the multivariate test Hotelling-LawleyTrace, there was an overall difference between the two groups: $F$ $=3.94, p=0.03$. When $\log \mathrm{T}_{3}$ and $\log \mathrm{T}_{4}$ were considered separately in an analysis of covariance, there was a significant difference between the two groups for $\log T_{3}$ after adjusting for birth weight and gestational age $(F=7.98, p=0.008)$. However, for $\log \mathrm{T}_{4}$ and TSH, there was no difference between the IRDS and control infants. These findings exclude the possibility of antenatal thyroid dysfunction in babies with IRDS. An explanation for reduced cord blood $T_{3}$ concentration in infants with IRDS

Received November 11, 1983; accepted February 10, 1984.

Correspondence may be addressed to Val Abbassi, M.D., Department of Pediatrics, Georgetown University Hospital, 3800 Reservoir Road, N.W., Washington, D. C. 20007.

D. C.
\end{abstract}

is lacking at present. Extrathyroidal factors that predispose to IRDS may also affect peripheral $T_{3}$ generation. Alternatively, one might postulate that there is relative immaturity of both peripheral $\mathrm{T}_{3}$ generating pathway and lung development in infants who develop IRDS.

\section{Abbreviations}

\section{TSH, thyrotropin}

$T_{3}$, triiodothyronine

$\mathrm{T}_{4}$, thyroxine

IRDS, idiopathic respiratory distress syndrome

Because of the apparent role of thyroid hormones in lung maturation (7), cord blood content of iodothyronines and TSH has been extensively evaluated with interest. Several investigators have found reduced thyroid hormone concentration in cord blood of such babies $(4,5,14)$. Thus, they have suggested a thyroid role in the pathogenesis of IRDS. Such findings have been disputed by others $(9,10)$. In a previous study, we reported that cord blood $\mathrm{T}_{3}$ concentration in babies with IRDS was lower 
than those without IRDS (1). However, the number of observations was small and the statistical methods for comparison of the data has been criticized (9). The important question that is still unresolved is whether the thyroid hormone level difference found in these babies are antecedent to the development of IRDS. This study was undertaken to further evaluate the question of antenatal thyroid dysfunction in IRDS.

\section{MATERIALS AND METHODS}

Cord blood samples obtained from preterm infants by one of the investigators (J. A.) as part of another study was utilized for measurement of $\mathrm{T}_{4}, \mathrm{~T}_{3}$, and TSH by radioimmunoassay methods previously described $(2,11,13)$. The assays were run simultaneously to eliminate the interassay variability. The intra-assay variability ranged from $2-5 \%$. The sensitivity for $\mathrm{T}_{4}$ assay was $0.10 \mu \mathrm{g}$, for TSH $0.4 \mu \mathrm{U}$, and for $\mathrm{T}_{3} 0.1 \mathrm{ng} / \mathrm{ml}$. Gestational age was calculated from the date of the mother's last menstrual period and was confirmed by the criteria of Dubowitz et al. (6). Birth weights were obtained on all infants. The babies were then classified into different groups based on gestational age and diagnosis. Twenty-one infants with IRDS and 15 healthy controls were included in this study. The IRDS control groups were not preselected or postselected to match for gestational age. Statistical significance was determined using the general linear models procedure in the statistical computing package SAS $(8,13)$.

\section{RESULTS}

Gestational age varied from 26 to 36 weeks in the IRDS group and from 28 to 36 weeks in the control group. Only two babies from IRDS group were below 28-week gestational age. Birth weight ranged from 670 to $2740 \mathrm{~g}$ in the IRDS group and from 800 to $2822 \mathrm{~g}$ in the control group. Cord blood $\mathrm{T}_{3}, \mathrm{~T}_{4}$, and TSH concentrations are shown in Table 1.

There was an overall difference between the two groups when $\mathrm{T}_{3}$ and $\mathrm{T}_{4}$ were considered as the dependent variables in the multivariate Hotelling-Lawley-Trace $F$ approximation test: $F=$ 3.94, $p=0.03$. $\log \mathrm{T}_{3}$ and $\log \mathrm{T}_{4}$ were then considered separately in an analysis of covariance. There was a significant difference between the two groups for $\log \mathrm{T}_{3}$ after adjusting for birth weight and gestational age: $F=7.98$ on $1.32 \mathrm{df} ; p=0.008$. However, for $\log \mathrm{T}_{4}$, there was no difference between the IRDS and control groups and neither was there any difference for log TSH.

There was no correlation between $\log \mathrm{T}_{3}$ and gestational age $(r=0.033, p=0.88), \log \mathrm{T}_{3}$ and $\log$ birth weight $(r=0.046, p$ $=0.84)$ in the IRDS group or in the control group $(r=0.346, p$ $=0.2$ and $r=0.128, p=0.64$ for $\log \mathrm{T}_{3}$ and gestational age and $\log \mathrm{T}_{3}$ and $\log$ birth weight, respectively).

\section{DISCUSSION}

Serum concentrations of thyroid hormones and TSH in cord blood from infants with IRDS have been extensively studied and compared to those of healthy preterm infants. Several studies report that cord blood $\mathrm{T}_{3}$ is decreased in preterm infants with IRDS $(1,4,14)$. Klein et al. (9) found no significant difference in cord serum $T_{3}$ concentrations from babies with IRDS. The

Table 1. Cord serum $T_{3}, T_{4}$, and TSH concentrations in IRDS and control infants*

\begin{tabular}{cccc}
\hline & $\mathrm{T}_{3}(\mathrm{ng} / \mathrm{dl})$ & $\mathrm{T}_{4}(\mu \mathrm{g} / \mathrm{dl})$ & $\mathrm{TSH}(\mu \mathrm{U} / \mathrm{ml})$ \\
\hline \multirow{2}{*}{ IRDS } & 16.8 & 5.5 & 9.9 \\
& $(11.9-23.7)$ & $(4.8-6.3)$ & $(8.0-11.6)$ \\
& $n=21$ & $n=21$ & $n=19$ \\
Control & 40.3 & 6.4 & 9.7 \\
& $(26.9-60.5)$ & $(5.5-7.6)$ & $(7.3-13.3)$ \\
& $n=15$ & $n=15$ & $n=12$ \\
\hline
\end{tabular}

* Values are geometric mean with $95 \%$ confidence intervals. $n$, number of samples. data with respect to $T_{4}$ is similarly conflicting. Some investigators have found reduced concentration $(4,15)$ while others have failed to demonstrate a significant difference $(1,9,10)$. Cord blood TSH levels are consistently higher in preterm babies relative to term gestation but are variably described as insignificantly changed (14) or relatively increased $(4,5)$ in IRDS.

That gestational age may account for some of the reported variations is suggested by the studies of Cuestas et al. (4). The reported differences in cord serum concentrations (decreased $\mathrm{T}_{3}$ and $\mathrm{T}_{4}$ and increased TSH) were significant only in comparisons involving infants of 33 to 37 weeks gestational age, and were insignificant in more premature groups. In the report by Klein et al. (9), infants with IRDS between 31 and 34 weeks gestation were studied and compared to an equal number of matched controls.

In this study of 21 babies with IRDS, equal numbers of control babies were not used and the control and IRDS groups were not preselected or postselected to match for gestational age and birth weight. Instead, gestational age and $\log$ birth weight were included as covariates in an analysis of covariance. In their studies, Klein et al., in addition to $\mathrm{T}_{4}$ and $\mathrm{T}_{3}$, measured $\mathrm{rT}_{3}$, and included the results with the $\mathrm{T}_{3}, \mathrm{~T}_{4}$, and $\mathrm{TSH}$ data for comparison of thyroid function by the global Hotelling $T_{2}$ test. They found no significant difference, in any of the thyroid parameters measured, between the IRDS and control group (9). $\mathrm{T}_{3}$ and $\mathrm{rT}_{3}$ are primarily derived from peripheral $\mathrm{T}_{4}$ metabolism and their concentrations can vary independent of thyroid function. In addition, the extent of the contribution of thyroid gland to circulating $T_{3}$ in prenatal life is not known. For these reasons, we elected to subject the $T_{4}$, $\mathrm{TSH}$, and $\mathrm{T}_{3}$ data separately, after logarithmic transformation, to an analysis of covariance. We found no significant difference between $\mathrm{T}_{4}$ and TSH concentrations of the two groups; however, cord blood concentration of $\mathrm{T}_{3}$ was significantly decreased in infants with IRDS. In the face of normal for gestational age concentrations of $\mathrm{T}_{4}$ and TSH in IRDS babies, thyroid dysfunction antecedent to the postnatal development of IRDS can be excluded. The observation that abnormal thyroid function does not persist in premature infants following recovery from IRDS is consistent with this view (3).

An explanation of the low $\mathrm{T}_{3}$ concentration in cord blood of IRDS babies is lacking at present. The maturational processes involved in the production of both surfactant and $T_{3}$ are gestational age dependent. Therefore, one can only postulate that extra thyroidal factors that predispose to IRDS may also affect $T_{3}$ generation. The possibility remains, however, that the low $T_{3}$ concentration may contribute to surfactant deficiency and to the pathogenesis of IRDS.

Acknowledgment. The material utilized for radioimmunoassay of $\mathrm{T}_{3}$ and $\mathrm{T}_{4}$ was kindly provided by Meloy Laboratories, Springfield, VA.

\section{REFERENCES}

1. Abbassi V, Merchant K, Abramson D 1977 Postnatal triiodothyronine concentration in healthy preterm infants and in infants with respiratory distress syndrome. Pediatr Res 11:802

2. Abbassi V, Aldrige C 1977 Evaluation of sodium L-thyronine requirement in replacement therapy of hypothyroidism. J Pediatr 90:298

3. Chowdhry P, Auerback A, Scanlon J, Abbassi V 1984 Results of controlled double blind study of thyroid replacement in very low birth weight premature infants. Pediatrics 73:301

4. Cuestas PA, Lindall A, Engel RR 1976 Low thyroid hormones and respiratory distress syndrome of the newborn. Studies on cord blood. N Engl J Med 295:297

5. Cuestas RA, Engel RR 1979 Thyroid function in preterm infants with respiratory distress syndrome. J Pediatr 94:643

6. Dubowitz LMS, Dubowitz V, Goldberg C 1970 Clinical assessment of gestational age in the newborn infant. J Pediatr 77:1

7. Gross I 1979 The hormonal regulation of fetal lung maturation. Clin Perinatol $6: 377$

8. Helwig JT, Council KA (eds) 1979 SAS Users Guide, 1979 ed. SAS Institute, Cary, NC Inc

9. Klein AH, Foley B, Foley TP, MacDonald HM, Fisher DA 1981 Thyroid function studies in cord blood from premature infant with and without RDS. J Pediatr 98:818 
10. Klein AH, Foley B, Kenny FM, Fisher DA 1979 Thyroid hormone and thyrotropin responses to parturition in premature infants with and without the respiratory distress syndrome. Pediatrics 63:380

11. Larsen PR 1973 Immunoassay of thyroxine in unextracted human sera. J Clin Endocrinol Metab 37:177

12. Morrison DF 1967 Multivariate Statistical Methods. McGraw Hill Book Com- pany, Inc, New York

13. Patel YC, Burger HG, Hudson B 1971 Radioimmunoassay of serum thyrotropin: sensitivity and specificity. J Clin Endocrinol Metab 33:768

14. Redding RA, Pereira C 1974 Thyroid function in respiratory distress syndrome of the newborn. Pediatrics 54:423

\title{
Respiratory Metabolism in Preterm Infants: the Measurement of Oxygen Consumpton during Prolonged Periods
}

\author{
Y. M. ABDULRAZZAQ AND O. G. BROOKE \\ Department of Child Health, St George's Hospital Medical School, Cranmer Terrace, London, \\ SW17 ORE, United Kingdom
}

\begin{abstract}
Summary
We have developed a method for measuring oxygen consumption $\left(\dot{\mathrm{V}}_{2}\right)$ in preterm infants in their normal incubator environment over prolonged periods. The results of measurements made over $\mathbf{2 4} \mathrm{h}$ in 18 infants are presented. In normally grown infants, the mean $\dot{\mathrm{V}}_{\mathrm{O}_{2}}$ was $9.66 \pm 1.25$ liters $/ \mathrm{kg} \cdot 24 \mathrm{~h}$ (SD) $(6.71 \pm 0.87$ $\mathrm{ml} / \mathrm{kg} \cdot \mathrm{min})$, and in small for gestation infants it was $10.09 \pm$ 1.21 liters $/ \mathrm{kg} \cdot 24 \mathrm{~h}(7.00 \pm 0.84 \mathrm{ml} / \mathrm{kg} \cdot \mathrm{min})$. During the $24-\mathrm{h}$ measurements, the highest mean $\dot{\mathrm{V}}_{2}$ during 3 consecutive $h$ was $7.75 \pm 0.89 \mathrm{ml} / \mathrm{kg} \bullet \mathrm{min}$ and the lowest was $5.95 \pm 0.92 \mathrm{ml} /$ $\mathrm{kg} \bullet \mathrm{min}$. The difference between the highest and the lowest values was significant $(p<0.001)$. There is room for considerable error if short term measurements are assumed to represent values over a whole day. "Short" measurements should be made over at least $6 \mathrm{~h}$.
\end{abstract}

\section{Abbreviations}

$\dot{\mathrm{V}}_{2}$, oxygen consumption rate

MR, metabolic rate

ME, metabolizable energy intake

$R Q$, respiratory quotient

The measurement of oxygen consumption in neonates is useful in assessing the optimum environmental conditions in which to nurse them $(4,6-8,18)$, and in making calculations of their energy expenditure, which, in conjunction with nutritional balances, can be used to determine the composition of their growth $(3,5,12,13,15)$. Many different techniques have been used to study respiratory metabolism $(2,9-11,14,16,17,19-21,23)$ but all have the dual drawbacks of disturbing the infant's normal environment and of being limited to a maximum period of only a few hours. If such measurements are to be used to their best advantage, they must accurately reflect the infant's $\dot{\mathrm{VO}}_{2}$ over much longer periods and in his normal environment. It is not at all certain that they do. We have recently developed a method

Received July 5, 1983; accepted February 7, 1984.

Requests for reprints may be addressed to Dr. O. G. Brooke, Department of Child Health, St George's Hospital, London, SW 17 ORE, United Kingdom.

Y. M. A. is supported by a grant from the Ministry of Education, United Arab Emirates. for measuring $\dot{\mathrm{V}}_{2}$ over prolonged periods in a normal nursing incubator (1) and this paper examines the differences between these prolonged measurements and measurements made over shorter periods of time.

\section{MATERIALS AND METHODS}

The method for $\dot{\mathrm{V}}_{2}$ measurement has been described previously (1). The principle is that a normal nursing incubator acts as a metabolic chamber for open circuit indirect calorimetry. The incubator used is a Vickers 79 (Vickers Medical Ltd, Basingstoke, England) but any incubator with good internal air circulation could probably be substituted. Access holes are sealed during the measurement period and under these conditions a slight negative pressure can be generated within the canopy by extracting air through a large bore tube at a sufficient rate $(\sim 12$ liters/min). This ensures that all expired air is removed for respiratory gas measurements. A large stable pump and accurate flow measurements are essential. Mixed expired air is sampled automatically by a solenoid-operated cycling device and is compared with reference air (room air) in alternating 2-min cycles. Oxygen concentration is measured with a paramagnetic analyzer (Taylor Servomex, Crowborough, England) and continuous comparisons are made between the concentration in reference air and mixed expired air by an integrating computer. The sensitivity of the Servomex analyzer is $1 \%$ of full scale deflection. Using zero suppression and suitable electrical amplification, full scale deflection can be adjusted to the range $0-0.5 \%$ of oxygen. In this range, sensitivity of $5 \times 10^{-3} \%$ can be achieved. $\mathrm{VO}_{2}$ is then calculated in the usual way, from the measured reduction in $\mathrm{O}_{2}$ concentration in the mixed expired air and the rate of extraction of air from the incubator. Metabolic rate is derived from the $\dot{\mathrm{VO}}_{2}$ measurements, the RQ being determined from simultaneous $\mathrm{CO}_{2}$ determinations if available, or assumed to be 0.9 .

The system was calibrated by burning butane at physiological rates of $\mathrm{O}_{2}$ consumption. Calibrations for the studies are shown in Table 1. Mean error was $4.3 \%$. Maximum measured error was $6.8 \%$. As would be expected, the error was always negative with respect to the absolute measured rate of $\mathrm{O}_{2}$ consumption (assessed by the weight of gas burned). This probably reflects a 